\title{
A new identification method of the supply hole discharge coefficient of gas bearings
}

\author{
G. Belforte, F. Colombo, T. Raparelli, A. Trivella \& V. Viktorov \\ Department of Mechanics, Politecnico di Torino, Italy
}

\begin{abstract}
The paper shows a new methodology to identify the orifice discharge coefficient of pneumatic externally pressurized bearings. A common method of identification is to measure the experimental air flow, the supply pressure and the local maximum of the pressure distribution in the bearing clearance near the supply hole. This method however involves some practical difficulties especially with small supply hole diameters due to the high pressure and velocity gradients near the supply holes. The proposed new method requires both theoretical and experimental approaches. It differs from the previous method because the experimental activity involves measuring only the pressure in correspondence of one specified point under the pad far from supply holes. The pressure distribution under the pad is calculated by solving the Reynolds equation. The pressure boundary condition near the supply holes and consequently the pressure distribution in the pad clearance depend on the supply hole discharge coefficient. By using the bisection method the discharge coefficient value is changed iteratively in order to find the convergence of the experimental pressure value with the numerical one. The discharge coefficient is obtained when the experimental pressure measured in the selected point corresponds with the calculated one. This new method is simpler to realize experimentally and it is less sensitive to the position of the measuring hole. Air pads with different supply hole diameters are tested. The pressure distribution under the pads is determined experimentally using a test bench at the purpose realized. The tests are carried out with different air clearances and supply pressures.
\end{abstract}

Keywords: pneumostatic air pad, discharge flow coefficient, gas lubrication, gas bearing. 


\section{NOMENCLATURE}

$b \quad$ Critical pressure ratio

$c_{\mathrm{d}} \quad$ Discharge coefficient of supply orifices

$d \quad$ Supply orifice diameter

$d_{0} \quad$ Insert diameter

$k_{\mathrm{T}} \quad$ Temperature coefficient $=\sqrt{T^{0} / T}$

$l \quad$ Supply orifice length

$h \quad$ Air clearance

$q \quad$ Inlet mass flow rate per unit area

$r \quad$ Radial coordinate

$N \quad$ Number of supply orifices

$P \quad$ Absolute pressure

$P_{\mathrm{a}} \quad$ Absolute ambient pressure

$P_{\mathrm{s}} \quad$ Absolute supply pressure

$P_{\mathrm{c}} \quad$ Absolute supply orifice downstream pressure

$R^{0} \quad$ Gas constant $=287.6 \mathrm{~m}^{2} / \mathrm{s}^{2} \mathrm{~K}$

$T^{0} \quad$ Absolute temperature in normal condition

$T \quad$ Orifice upstream absolute temperature

Re Reynolds number

$S \quad$ Supply orifice cross section

$\vartheta \quad$ Circumferential coordinate

$\phi_{\mathrm{e}} \quad$ Pad external diameter

$\phi_{1} \quad$ Pad internal diameter

$\mu \quad$ Air viscosity $=17.8910^{-6} \mathrm{~Pa} \mathrm{~s}$

\section{Introduction}

Gas bearings are used for those applications in which high precision and repeatability in positioning are required. The absence of stick and slip and the very low friction makes these components very appropriate in precision linear guides. Externally pressurized air bearings are used to support measuring and testing machines and their static and dynamic performance is the object of continuous improvement in the design process.

While the equations that describe in good approximation the air flow in the clearance under the pad are well known, a problem not yet completely solved is the definition of the discharge coefficient of the supply holes. The researchers have dealt with this problem both experimentally and by means of numerical methods. In Al-Bauder and Van Brussel [1] an experimental activity on a centrally fed circular air pad is shown and compared with simulated results obtained with a method, called "separation of variables". A common approach consists in measuring empirically the discharge coefficient that relates the theoretical mass flow rate to the experimental one with the following formula

$$
G_{\exp }=c_{d} G_{t h}
$$


where the theoretical mass flow rate is calculated considering an isentropic expansion. Some papers present a single number, e.g. Lund [2] and Bryant et al. [3], while others propose empirical formulas, e.g. Elrod and Glanfield [4] and Kazimierski and Trojnarski [5]. Other authors like Renn and Hsiao [6], Belforte et al. [7] and Ly and Ding [8] solve the complete flow problem by using commercial CFD codes.

Belforte et al. [9] proposed a formula to calculate the discharge coefficient on the base of experimental measurements of mass flow rates and of pressure distributions near the supply holes. However this method presents some practical difficulties when the supply holes have a diameter smaller than $0.1 \mathrm{~mm}$.

In the present paper is proposed another identification method that needs to measure experimentally the pressure only in correspondence of one point under the pad. This method is simpler to be realized and less time consuming because it doesn't need to measure the pressure distribution under the pad near the supply holes, where the pressure gradients are very high.

\section{Pads under test}

Four annular stainless steel pneumatic pads are examined. They have the same outer diameter of $40 \mathrm{~mm}$ and inner diameter of $10 \mathrm{~mm}$. The central pocket is at ambient pressure.

Figure 1 shows the sketch of the pads and figure 2 their photo. In correspondence of the supply circumference of diameter $25 \mathrm{~mm}, N$ equispaced supply holes of diameter $d$ and length $l=0.4 \mathrm{~mm}$ are realized. The nominal diameter values are $0.2 \mathrm{~mm}, 0.3 \mathrm{~mm}, 0.4 \mathrm{~mm}$ and $0.2 \mathrm{~mm}$ for pads $1,2,3$ and 4 respectively. The holes are drilled on brass inserts of diameter $d_{0}=4 \mathrm{~mm}$.

Table 1: Geometric parameters.

\begin{tabular}{|c|c|c|c|c|c|}
\hline $\begin{array}{l}\text { Pad } \\
\text { type }\end{array}$ & $\begin{array}{c}\text { Number of } \\
\text { holes N }\end{array}$ & Orifice & $\begin{array}{c}\text { Measured } \\
\text { orifice diameter } \\
d_{\mathrm{m}}[\mathrm{mm}]\end{array}$ & $\begin{array}{c}\text { Mean diameter } \\
\text { value }[\mathrm{mm}]\end{array}$ & $\begin{array}{l}\text { Roughness } \\
\mathrm{Ra}[\mu \mathrm{m}]\end{array}$ \\
\hline \multirow{3}{*}{1} & \multirow{3}{*}{3} & 1 & 0.237 & \multirow{3}{*}{0.222} & \multirow{3}{*}{0.45} \\
\hline & & 2 & 0.211 & & \\
\hline & & 3 & 0.219 & & \\
\hline \multirow{3}{*}{2} & \multirow{3}{*}{3} & 1 & 0.312 & \multirow{3}{*}{0.313} & \multirow{3}{*}{0.46} \\
\hline & & 2 & 0.313 & & \\
\hline & & 3 & 0.315 & & \\
\hline \multirow{3}{*}{3} & \multirow{3}{*}{3} & 1 & 0.421 & \multirow{3}{*}{0.420} & \multirow{3}{*}{0.61} \\
\hline & & 2 & 0.415 & & \\
\hline & & 3 & 0.424 & & \\
\hline \multirow{6}{*}{4} & \multirow{6}{*}{6} & 1 & 0.228 & \multirow{6}{*}{0.221} & \multirow{6}{*}{0.38} \\
\hline & & 2 & 0.230 & & \\
\hline & & 3 & 0.212 & & \\
\hline & & 4 & 0.219 & & \\
\hline & & 5 & 0.218 & & \\
\hline & & 6 & 0.217 & & \\
\hline
\end{tabular}


In Table 1 are shown the principal geometric parameters of the pads. Each supply hole was measured by a microscope along two perpendicular directions and the mean value $d_{\mathrm{m}}$ is reported in the table with also the measured mean diameter value of all the orifices. In the table are reported also the relative errors with respect to the nominal values and the roughness of the pads.
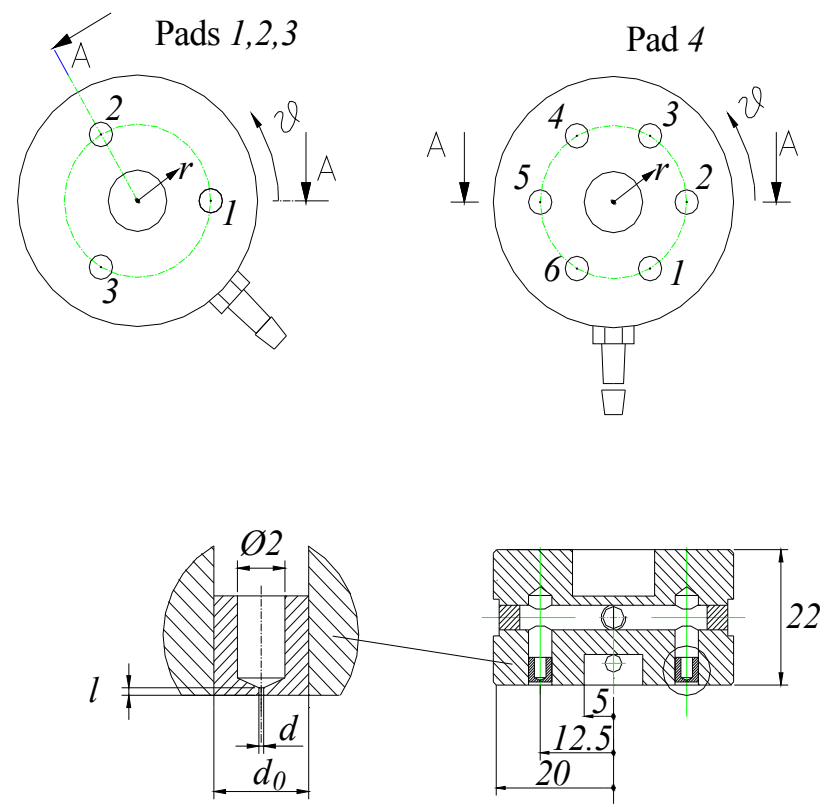

Figure 1: Sketch of the pads.

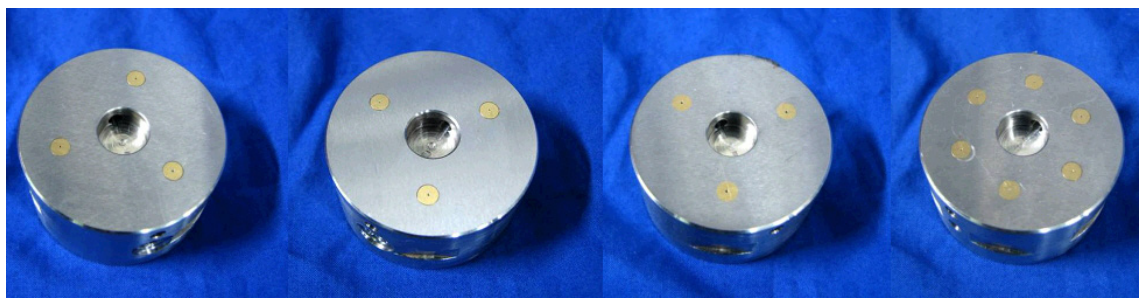

Figure 2: $\quad$ Photo of the pads.

\section{Numerical model}

The well known Reynolds equation (2) for compressible fluids is solved to calculate the pressure distribution under the pad.

$$
\frac{1}{r} \frac{\partial}{\partial r}\left(r h^{3} \frac{\partial P^{2}}{\partial r}\right)+\frac{1}{r^{2}} \frac{\partial}{\partial \vartheta}\left(h^{3} \frac{\partial P^{2}}{\partial \vartheta}\right)+24 \mu R^{0} T^{0} \frac{G}{r d r d \vartheta}=24 \mu \frac{\partial(P h)}{\partial t}
$$


Mass flow rate $G$ is calculated in accordance with the isentropic expansion equation (3), where $P_{\mathrm{c}}$ is the supply port downstream absolute pressure.

$$
\begin{aligned}
& G=c_{d} G_{t h}=c_{d} \pi \frac{d_{s}^{2}}{4} P_{s} \sqrt{\frac{k}{k-1}\left[\left(\frac{P_{c}}{P_{s}}\right)^{\frac{2}{k}}-\left(\frac{P_{c}}{P_{s}}\right)^{\frac{k+1}{k}}\right] \frac{2}{R T}} \text { if } \frac{P_{c}}{P_{s}} \geq 0.528, \\
& G=c_{d} G_{t h}=c_{d} \pi \frac{d_{s}^{2}}{4} P_{s} \sqrt{\left(\frac{2}{k+1}\right)^{\frac{2}{k-1}}\left(\frac{k}{k+1}\right) \frac{2}{R T}} \text { if } \frac{P_{c}}{P_{s}}<0.528 .
\end{aligned}
$$

The discharge coefficient $c_{\mathrm{d}}$ can be identified experimentally. In paper [9] the following formula is proposed

$$
c_{d}=0.85\left(1-e^{-8.2 \frac{h}{d}}\right)\left(1-e^{-0.001 \mathrm{Re}}\right)
$$

where Reynolds number is calculated with eqn (5)

$$
\mathrm{Re}=\frac{4 G}{\pi d \mu}
$$

If formula (4) is used coefficient $c_{\mathrm{d}}$ is calculated on the base of the mass flow rate $G$ of the previous iteration. Eqn (2) is discretized with finite difference method considering central derivatives. The surface under the pad is meshed with $n$ and $m$ nodes along the radial and the circumferential directions respectively. The position of the nodes is chosen in order to make some of them coincide with the supply holes. The Reynolds equation is solved with explicit Euler method with the initial condition of ambient pressure in correspondence of all nodes.

The following boundary conditions are considered:

- $\quad P=P_{\mathrm{a}}$ at the outer and inner edges of the pad

- coincidence of pressure for $\theta=0$ and $\theta=2 \pi$.

The load carrying capacity of the pad is calculated integrating the relative pressure under the pad with eqn (6):

$$
F=\int_{0}^{2 \pi} \int_{r_{i}}^{r_{e}}\left(P-P_{a}\right) r d r d \theta
$$

\subsection{Discharge flow coefficient identification}

In Belforte et al. [9] the discharge coefficient $c_{\mathrm{d}}$ was calculated with eqn (1) as the ratio between the experimental and the theoretical mass flow rate, obtained 
considering the experimental supply holes downstream pressure level $P_{\mathrm{c}}$. This method however requires to measure the pressure distribution near the supply holes and individuate with good precision the downstream pressure level $P_{\mathrm{c}}$. This could be difficult especially with small hole diameters because of the high pressure gradients. Moreover the measuring hole machined on the crossmember must have a smaller diameter than the supply hole in order to measure correctly the pressure distribution. This limits the diameter of the supply holes for the pads that can be tested correctly on the test bench.

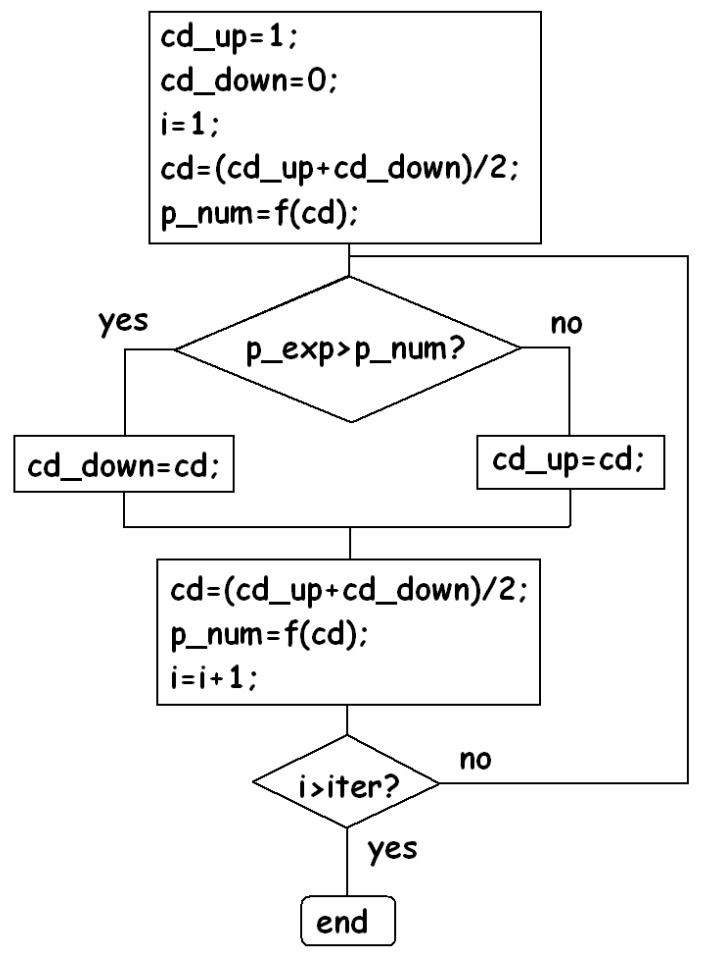

Figure 3: Block diagram of the identification algorithm.

A new method of identification of the supply holes discharge coefficient is proposed hereunder. The method consists in measuring the pressure $P_{\text {exp }}$ in correspondence of a determined point under the pad for different clearance values. This pressure is compared with the numerical value $P_{\text {num }}$ that one obtains with a discharge coefficient $c_{\mathrm{d}}$ of first approximation. The $c_{\mathrm{d}}$ value is then modified and the relative pressure is calculated numerically; different iterations are performed using the bisection method until convergence is reached. The final numerical discharge coefficient corresponds to a numerical pressure value equal to the experimental one. In figure 3 is shown the block diagram of the algorithm used. The number of iterations performed is iter $=8$, to which corresponds a convergence error $\operatorname{err}<0.2 \%$, where $\operatorname{err}=\left(P_{\exp }-P_{\text {num }}\right) / P_{\text {exp }}$. 


\section{Experimental set-up}

\subsection{Test rig description}

The test rig is composed of a rigid structure and a moving screw with which it is possible to impose different air clearance heights between the pad and the stationary member. The air gap is measured by means of two micrometric inductive probes with sensitivity $0.1 \mu \mathrm{m}$. The load carrying capacity of the pad is measured with a load cell with $2 \mathrm{kN}$ full range. The pressure under the pad is measured with a piezoresistive sensor with resolution $10^{-4} \mathrm{MPa}$, connected to the measuring hole drilled in the stationary pad (see figure 4). The latter can be moved radially or circumferentially in order to measure the pressure value in

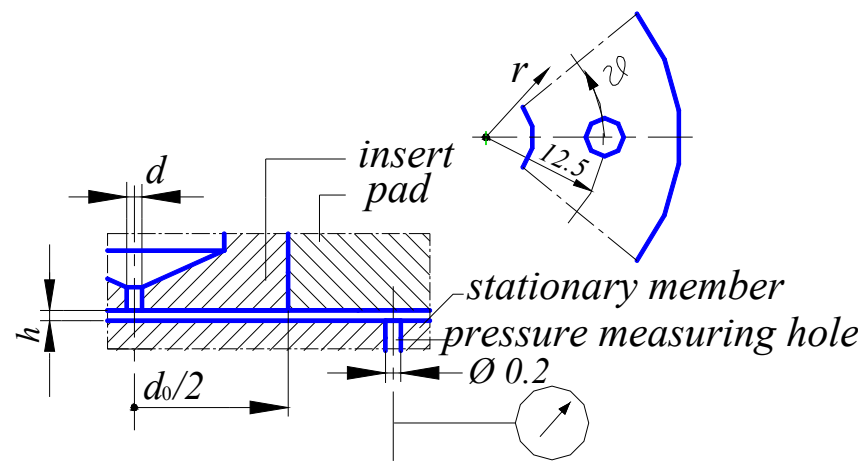

Figure 4: $\quad$ Sketch of the measuring system.

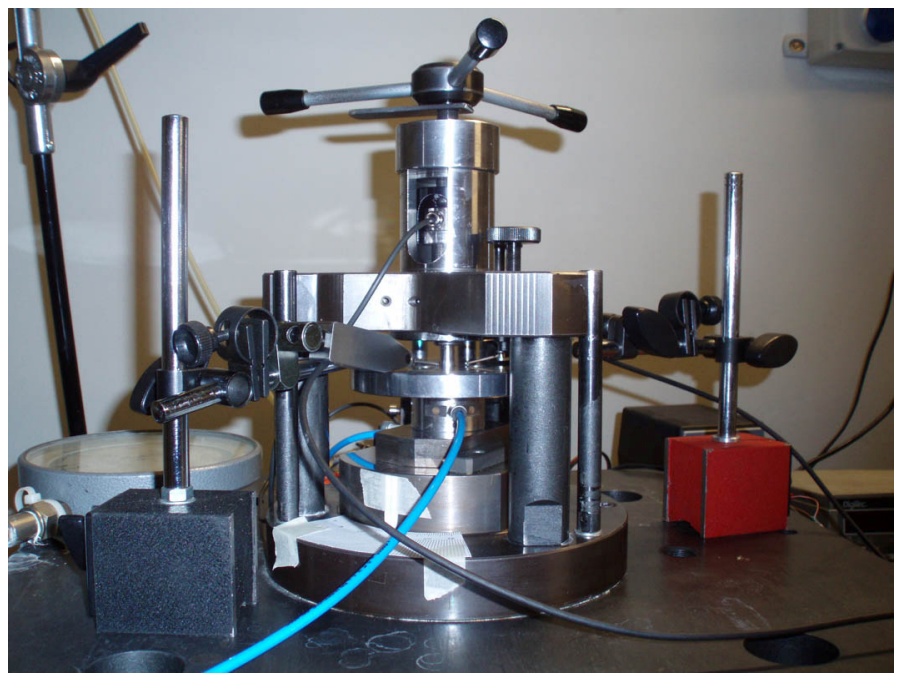

Figure 5: $\quad$ Test rig. 
each point under the pad. A potentiometric displacement transducer measures the radial position of the stationary member with respect to the center of the pad.

The air flow rate is measured by a flowmeter situated upstream the pad. High efficiency air filters ( $97 \%$ and $99 \%$ efficiency with particles of diameter $0.1 \mu \mathrm{m})$ are used to avoid problems of clogging of the supply holes. Figure 5 shows the test rig.

\subsection{Test procedure}

The load carrying capacity and the air consumption are strongly influenced by the air gap. For this reason a test procedure was defined in order to obtain a good repeatability and precision of the measurements.

The pad is initially cleaned and the supply holes are checked with a microscope to exclude an eventual clogging. The pad is then supplied with compressed air at a defined pressure and an increasing downwards vertical force is applied on it until the air clearance is equal to zero. In this condition the displacement transducers are set to zero. Higher loads are avoided in order not to deform the pad and the stationary member. In this way the reading of the displacement transducers coincides with the air clearance. The deformation of the pad and of the stationary member are negligible. The force applied to the pad is then decreased and the pressure under the pad, the load capacity and the air flow rate are measured for different air gaps. The supply pressure is maintained constant for each clearance value up to $h=20 \mu \mathrm{m}$. The measuring hole is positioned far away the supply holes where the pressure gradients are low. In particular it was positioned in correspondence of the supply circumference in the middle of two supply holes.

\subsection{Experimental results and discussion}

The pressure in correspondence of the measuring point was measured at different clearance values with $P_{\mathrm{s}}=0.6 \mathrm{MPa}$. In figure 6 the measured pressures under the

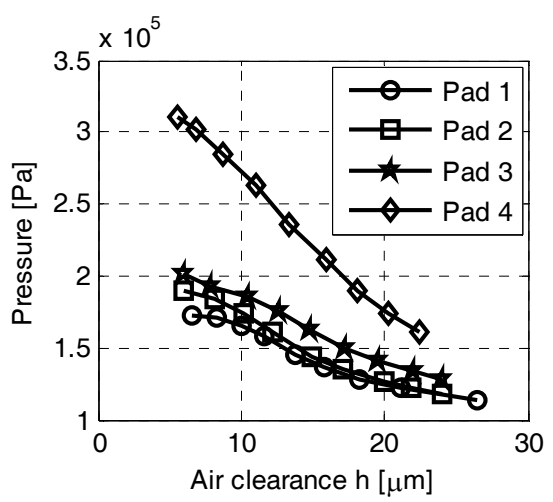

Figure 6: Experimental pressure in the measuring point under the pad vs air clearance; comparison between different pads. 
four pads are compared vs the air clearance. As one can see, the pressure increases both with the diameter of supply holes (pads 1 to 3 ) and with the number of holes (pads 1 and 4). The second effect is predominant.

In figure 7 the air mass flow rate is reported vs the air clearance. The air consumption of pad 4 is almost twice than that of pad 1, being the number of holes twice and the supply hole diameter the same. In figure 8 the experimental load capacity of the pads are compared with the numerical ones. The numerical solution underestimates the experimental load capacity.

In figure 9 the values of the discharge coefficients obtained with the proposed method are reported. The values are compared with the ones obtained with the empirical formula (4). Considering that the value of $c_{\mathrm{d}}$ is very sensitive to the clearance value $h$, the comparison is quite good. The error between the formula and the experimental value is comparable with the tolerance admitted.

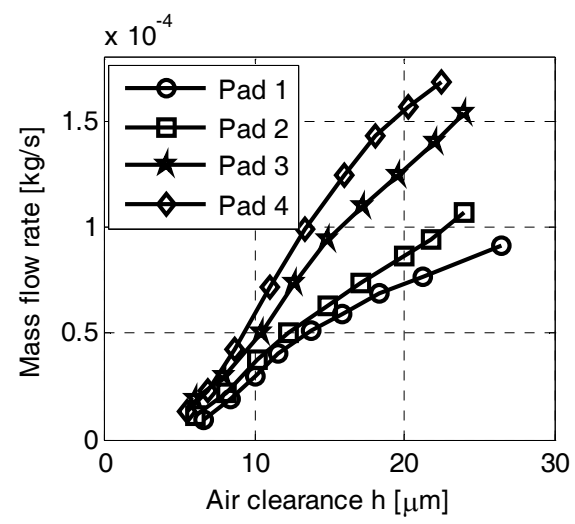

Figure 7: Experimental air consumption vs air clearance; comparison between different pads.

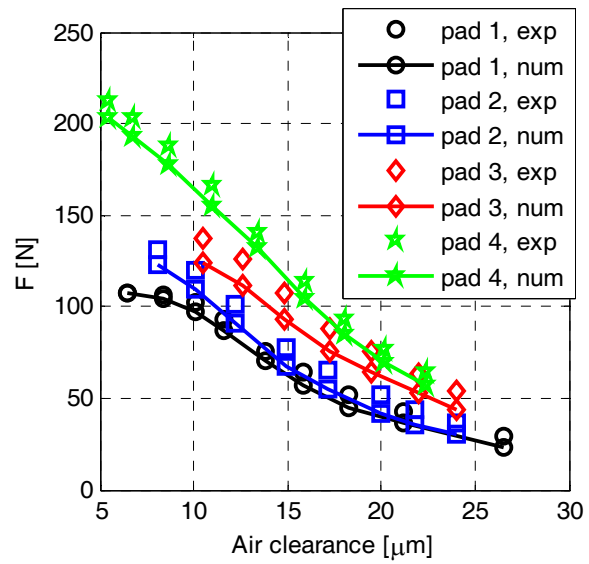

Figure 8: Load capacity vs air clearance; comparison between experimental and numerical results. 


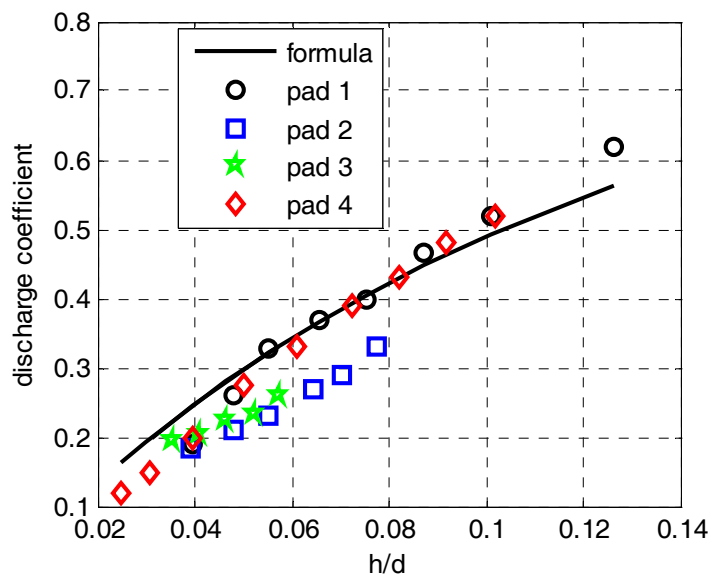

Figure 9: Discharge coefficient $c_{\mathrm{d}}$ vs air clearance; comparison between the values obtained with the identification method and with eqn (4).

\section{Conclusions}

A method of identification of the supply holes discharge coefficient for gas bearings is presented. The method allows the determination of the coefficient $c_{\mathrm{d}}$ without the need of measuring the complete pressure distribution under the supply holes. This involves some practical advantages that are more evident when the supply hole diameter is smaller than $0.1 \mathrm{~mm}$. The diameter of the measuring hole is not needed to be smaller than the supply hole diameter because the pressure is measured far-off the supply holes, where the pressure gradients are not high. As the air consumption and the pressure under the pad are very sensitive to the air clearance, the experimental measures must be carried on with carefulness in order to have a good estimation of the discharge coefficient.

\section{References}

[1] Al-Bauder, F., Van Brussel H., Symmetric radial laminar channel flow with particular reference to aerostatic bearings, Journal of Tribology, 114, pp. 630-636, 1992.

[2] Lund, J.W., The hydrostatic gas journal bearing with journal rotation and vibration, Journal of Basic Engineering, 86, pp. 328-336, 1964.

[3] Bryant, M.R., Velinsky, S.A., Beachley, N.H., Froncza, K.F.T., A design methodology for obtaining infinite stiffness in an aerostatic thrust bearing, Journal of Mechanisms, Transmissions and Automation in Design, 108, pp. 448-456, 1986.

[4] Elrod, H.G., Glanfield, G.H., Computer procedures for the design of flexibly mounted, externally pressurized, gas lubricated journal bearing, Gas bearing Symposium, University of Southampton, pp. 22.1-22.37, 1971. 
[5] Kazimierski, Z., Trojnarski, J., Investigation of externally pressurized gas bearing with different feeding systems, Journal of Lubrication Technology, 102, pp. 59-64, 1980.

[6] Renn., J., Hsiao, C., Experimental and CFD study on the mass flow-rate characteristic of gas through orifice-type restrictor in aerostatic bearings, Tribology International, 37, pp. 309-315, 2004.

[7] Belforte, G., Raparelli, T., Trivella, A., Viktorov, V., Visconte, C., Numerical analysis on the supply hole discharge coefficient in aerostatic bearings, International Conference on Tribology AITC-AIT 2006, 20-22 September 2006, Parma, Italy.

[8] Ly, Y., Ding, H., Influences of the geometrical parameters of aerostatic thrust bearing with pocketed orifice-type restrictor on its performance, Tribology International, 40, pp. 1120-1126, 2007.

[9] Belforte, G., Raparelli, T., Viktorov, V., Trivella, A., Discharge coefficients of orifice-type restrictor for aerostatic bearings, Tribology International, 40, pp. 512-521, 2008. 